\title{
Preservation of canine lung for re-implantation using hypothermia and hyperbaric oxygen

\author{
Survival following contralateral pneumonectomy
}

\author{
C. A. ROSS AND R. FABIANO ALVES \\ From the Division of Thoracic and Cardiovascular Surgery of the Department of Surgery and the \\ Surgical-Medical Research Institute of the University of Alberta, Edmonton, Alberta
}

Forty dogs were submitted to left pneumonectomy. The resected lungs were subjected to varying periods of time in a hyperbaric and hypothermic chamber. Several variations of this method are described. The lungs were then re-implanted. The immediate and subsequent results as to function, microscopic and macroscopic findings, radiography, and radioisotope scans are mentioned. The survival time after contralateral resection is described.

Organ transplantation is moving from the theoretical and experimental to the clinical phase. As in most modern scientific achievement, work is progressing in many laboratories on many aspects of the problem.

It seems obvious from the results of experimental lung transplants and from the few human transplants that have been done that the ideal procedure is a direct transplant from the living or 'semi-living' donor. This involves practical problems. It seems that some method of lung preservation during the 'donor-recipient interval' is advisable, if possible.

Since hypothermia plus hyperbaric oxygen has been used in the preservation of kidneys and lungs for transplantation (Blumenstock, Lempert, and Morgado, 1965 ; Nigro, Evans, Benfield, Gago, Fry, and Adams, 1963) it was decided to adopt this method.

We had previously developed the technique of immediate lung re-implantation to the point where we could regularly expect survival of these animals. We therefore decided to use auto-transplantation rather than homo-transplantation to evaluate the efficacy of this method of lung transplantation.

The logical criteria used to evaluate the procedure were (1) survival of the animal with a normal activity potential; and (2) a resultant normal or near-normal re-implanted lung. The first factor can be judged by abservation of the

1Civic Employees Association of Edmonton Fellow in Experimental Surgery, and also supported by a grant of the Canadian Tuberculosis Association surviving animals, although treadmill exercises would be more accurate.

The second must be determined by examining the following parameters:

1. Efficiency of $\mathrm{O}_{2}$ and $\mathrm{CO}_{2}$ exchange

2. Presence or absence of a Hering-Breuer reflex

3. Pulmonary artery pressures

4. Gross and microscopic appearance of the transplanted lung

5. Gross pulmonary circulation as evidenced by pulmonary angiography

6. Lung scans using micro-aggregated serum albumin tagged with radioactive ${ }^{131} I$

7. Blood-gas studies.

\section{MATERIALS AND METHODS}

In the present series of experiments 40 mongrel dogs were used. These animals were picked for their general health and size. The average dog weighed between 17 and $20 \mathrm{~kg}$.

Three variations of the method of preservation in the hyperbaric oxygen chamber were used:

GROUP 1 Preservation using hyperbaric oxygen, hypothermia with perfusion, and positive pressure ventilation (4 cases).

GROUP 2 Preservation using hyperbaric oxygen, hypothermia, and perfusion ( 7 cases).

GROUP 3 Preservation using hyperbaric oxygen and hypothermia with simple preliminary washing out of the lung with heparinized saline containing one 
million units of crystalline penicillin per $1,000 \mathrm{ml}$. of solution (33 cases).

The last group was divided into two sub-groups: (a) in six of these animals the lung was kept in the chamber in an inflated condition; $(b)$ in 27 the lung was placed in the chamber in the deflated condition.

\section{IMMEDIATE RESULTS}

Of group 1 there were no long-term survivors and at necropsy 11 animals showed massive infarction of the re-implanted lung. We believe that this originated from thrombosis in the venous side of the graft.

Of group 2 there were no long-term survivors. Four deaths were due to vascular thrombosis. One was due to mediastinal emphysema and one to pneumothorax secondary to a leak at the bronchial anastomosis.

Of group $3 \mathrm{a}$ there were no long-term survivors. One dog died from atelectasis with endobronchial blood clot and pneumothorax. The chest tube accidentally came out during a period of restlessness of the dog. One dog died one month postoperatively with broncho-stenosis and suppurative pneumonitis. One died of haemorrhage due to slipping of the left arterial clamp during operation. One dog died of pulmonary artery thrombosis. Two dogs died of venous thrombosis.

Of group $3 b$ seven dogs died. There were 20 long-term survivors. The deaths were due to anaesthetic or operative problems or to immediate post-operative problems.

Of the 20 survivors, four were sacrificed without respiratory function studies. These animals were sacrificed four to six months post-operatively and at necropsy the re-implanted lung appeared grossly normal except that in one case there was upper lobe fibrosis secondary to upper vein stenosis, and in all dogs the re-implanted lung showed a few patchy areas of fibrosis (Fig. 1).

Histological studies showed that in general the re-implanted lung appeared normal except for some peri-bronchial smooth muscle hypertrophy and pleural 'thickening'. There were also small patchy areas of what appeared to be organized infarcts.

All of these dogs were subjected to one hour of hypothermia and hyperbaric oxygen with an average ischaemic time of 2 hours 30 minutes.

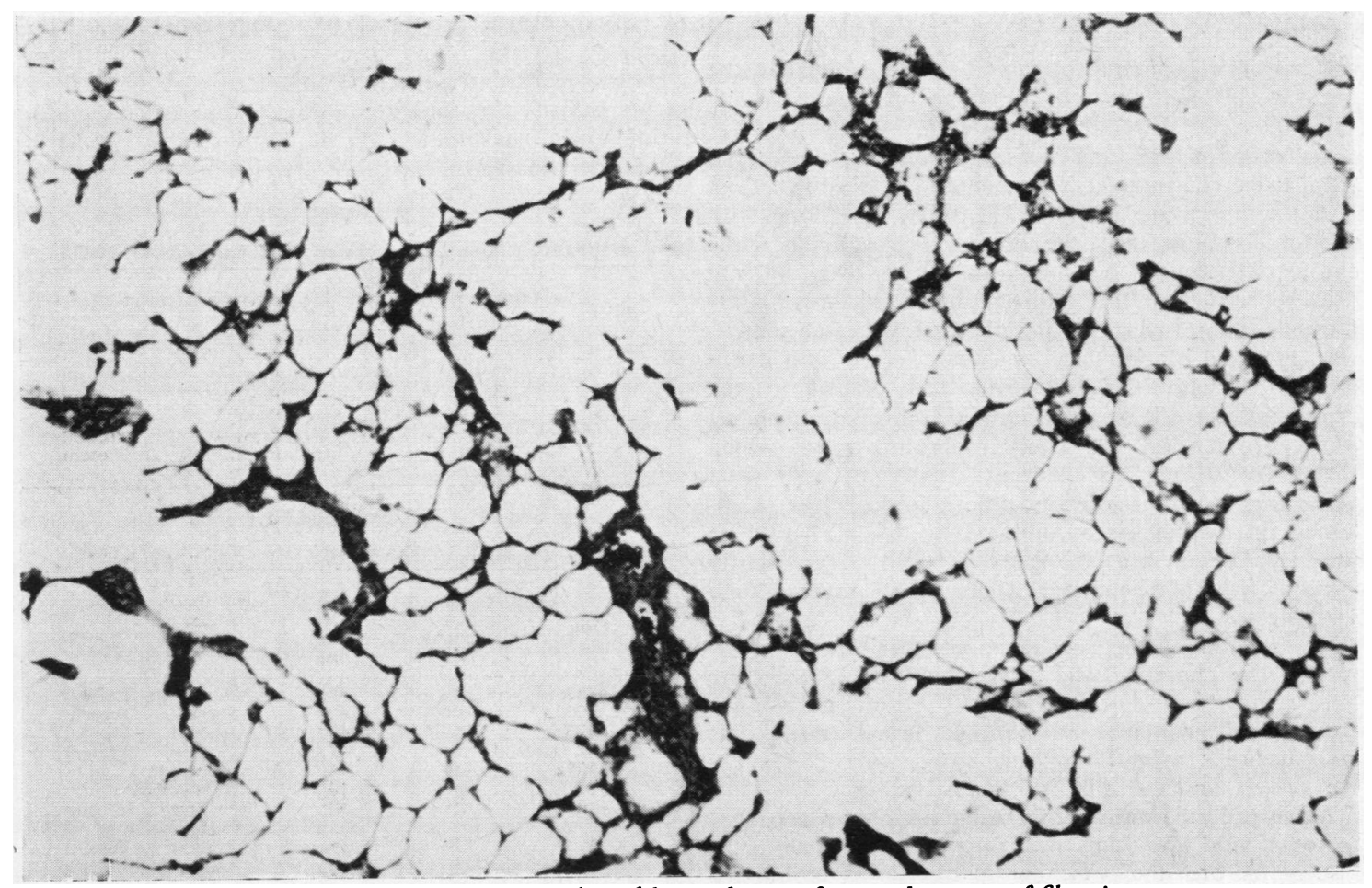

FIG. 1. Microscopical examination of the re-implanted lungs shows a few patchy areas of fibrosis. 
One dog was injured in a fight with another dog and had aspirated blood into the right lung. This dog died of mediastinal emphysema secondary to tracheal laceration. At necropsy the upper lobe of the re-implanted lung was fibrotic with occlusion of the vein at its entrance into the left atrium. The lower lobe was grossly and microscopically normal.

In the remaining 15 surviving dogs, all reimplanted lungs had been subjected to from $1 \frac{1}{2}$ to 2 hours of hypothermia and hyperbaric oxygen with an average ischaemic time of 3 to $4 \frac{1}{2}$ hours.

Since it appears obvious that the greatest success was achieved in this group, the surgical technique will be described.

\section{SURGICAL TECHNIQUE}

Using nembutal anaesthesia and cuffed endotracheal intubation, the animal was maintained on room air with the automatic respirator. Left thoracotomy was performed, resecting the sixth rib or going through the sixth rib bed without resecting the rib. Pneumonectomy was carried out, first dissecting out the pulmonary artery, the bronchus, and the entrance of the pulmonary veins into the left atrium. The pulmonary artery was injected with $2 \mathrm{ml}$. of heparin and was immediately clamped. The atrial clamp was then placed to include as large a cuff of left atrium as possible (Métras, 1950). The pulmonary artery was divided. The bronchial clamp was placed distal to the tracheal bifurcation and the bronchus was divided. The atrio-venous cuff was divided.

As soon as the lung was removed, it was flushed with the heparinized saline-penicillin solution at an initial temperature of $4^{\circ} \mathrm{C}$. Flushing was done with a 50-ml. syringe until the lung was a uniform white colour. It should be mentioned that this did not always result in the entire lung being adequately flushed. There were frequently a few patchy areas with retained blood. The lung was covered with gauze moistened with the perfusate and placed in the chamber, where it was maintained at three atmospheres of oxygen tension and at a temperature range which varied from $0^{\circ} \mathrm{C}$. to $4^{\circ} \mathrm{C}$.

During the preservation time the dog was maintained on the respirator under anaesthesia. The chest was left open, but the pleural cavity was lightly packed with saline-moistened gauze and covered with a sterile towel.

At the end of the predetermined period of preservation, the chamber was decompressed and the lung was removed and re-implanted. Atrial, pulmonary artery, and bronchial anastomoses were carried out in that order using a running suture of 5-0 silk for the vessels and 4-0 silk for the bronchus.

After re-implantation the bronchus clamp was first removed and the lung was allowed to inflate completely before the vascular clamps were removed. The chest was closed with intercostal drainage which was left on suction until the dog began to recover from anaesthesia. The chest tube was removed the following day.

\section{PULMONARY FUNCTION STUDIES}

The time of performing pulmonary function studies varied from four months to one year post-operatively (Table I)

T A B L E I

POST-OPERATIVE PULMONARY FUNCTION STUDIES

\begin{tabular}{lc}
\hline Dog & Time Interval (mths.) \\
\hline C-838 & 11 \\
C-1066 & 9 \\
D-325 & 9 \\
D-1092 & 8 \\
D-320 & 4 \\
D-325 & 4 \\
C-513 & 12 \\
D-32 & 7 \\
& 6 \\
\hline
\end{tabular}

Bronchospirometry and cardiac catheterization in all cases were done under chloralose anaesthesia. Blood gases were done on the unanaesthethized animal. The Robertshaw double-lumen right-sided tube (Fig. 2a) was found to be most satisfactory. The Hering-Breuer reflex was tested by clamping the tube leading from the lung to be tested when the lung was in full inspiration (Fig 2b).

In a control group of five dogs differential spirometry, arterial blood gases, and right heart catheterization were carried out (Table II).

Nine of the operated dogs were subjected to differential spirometry. Table III lists the results of this examination.

T A B L E I I

DIFFERENTIAL SPIROMETRY IN CONTROL DOGS

\begin{tabular}{c|c|c|c|c}
\hline \multirow{2}{*}{$\begin{array}{c}\text { Control } \\
\text { Dog }\end{array}$} & \multicolumn{2}{|c|}{ Oxygen Uptake (\%) } & \multicolumn{2}{c}{ Hering-Breuer Reflex } \\
\cline { 3 - 5 } & Right Lung & Left Lung & Right Lung & Left Lung \\
\hline 1 & 51 & 49 & Present & Present \\
2 & 64 & 36 & Present & Present \\
3 & 68 & 32 & Present & Present \\
4 & 50 & 50 & Present & Present \\
5 & 54 & 46 & Present & Present \\
\hline
\end{tabular}

T A B L E I I I

DIFFERENTIAL SPIROMETRY IN OPERATED DOGS

\begin{tabular}{|c|c|c|c|c|}
\hline \multirow{2}{*}{ Dog } & \multicolumn{2}{|c|}{ Oxygen Uptake ( $\%)$} & \multicolumn{2}{|c|}{ Hering-Breuer Reflex } \\
\hline & $\begin{array}{l}\text { Right } \\
\text { Lung }\end{array}$ & $\begin{array}{c}\text { Left } \\
\text { Lung }\end{array}$ & $\begin{array}{l}\text { Right } \\
\text { Lung }\end{array}$ & $\begin{array}{l}\text { Left } \\
\text { Lung }\end{array}$ \\
\hline $\begin{array}{l}\text { C-838 } \\
\text { C-1006 } \\
\text { D-325 } \\
\text { D-32 } \\
\text { D-1092 } \\
\text { C-97 } \\
\text { C-1002 }\end{array}$ & $\begin{array}{l}56 \\
60 \\
59 \\
53 \\
57 \\
90 \\
50\end{array}$ & $\begin{array}{l}44 \\
40 \\
41 \\
47 \\
43 \\
10 \\
50\end{array}$ & \multirow{2}{*}{\multicolumn{2}{|c|}{ 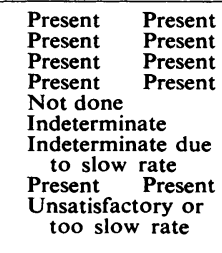 }} \\
\hline $\begin{array}{l}C-513 \\
D-320\end{array}$ & $\begin{array}{l}54 \\
60\end{array}$ & $\begin{array}{l}46 \\
33\end{array}$ & & \\
\hline
\end{tabular}




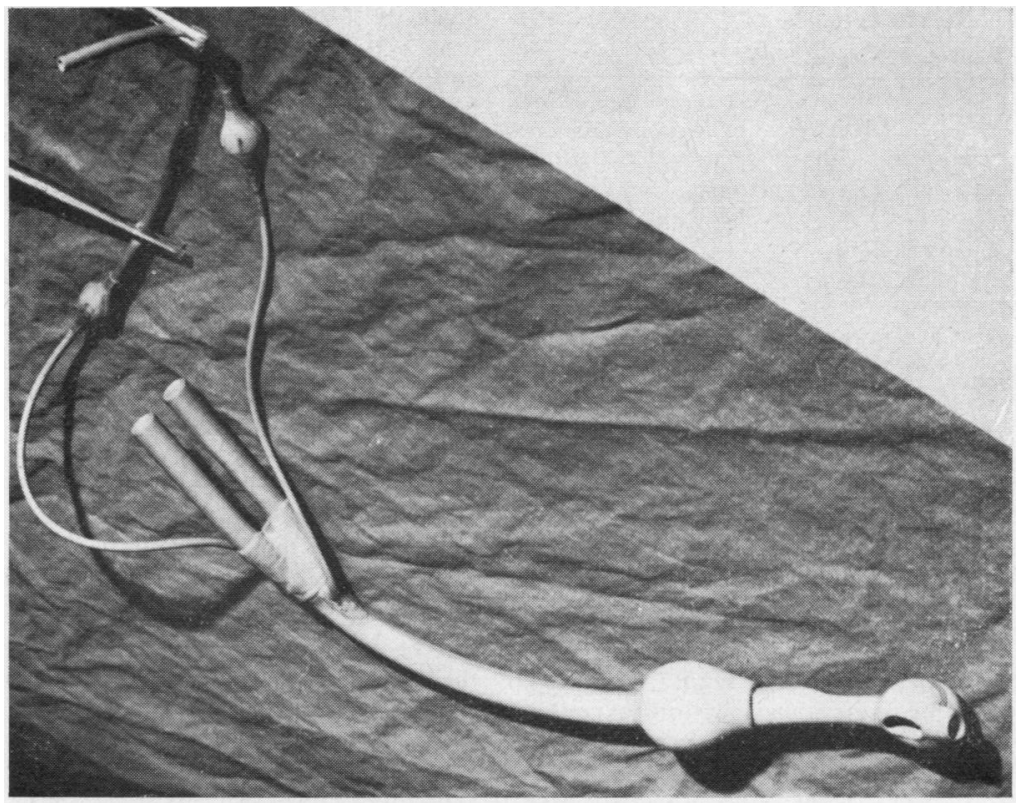

FIG. 2a. The Robertshaw double-lumen right-sided tube.

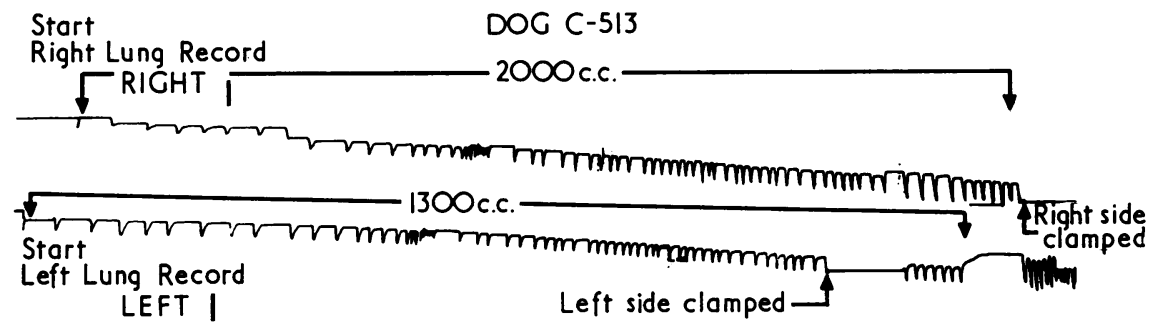

FIG. 2b. Spirographic tracing of differential spirometry showing contralateral Hering-Breuer reflex.

T A B L E I V

CARDIAC CATHETERIZATION

\begin{tabular}{|c|c|c|c|c|c|c|c|}
\hline \multirow{2}{*}{ Dog } & \multirow{2}{*}{$\begin{array}{l}\text { Right } \\
\text { Atrium } \\
\text { Mean } \\
(\mathrm{mm} . \\
\mathrm{Hg})\end{array}$} & \multicolumn{3}{|c|}{$\begin{array}{l}\text { Right Ventricle } \\
\text { (mm.Hg) }\end{array}$} & \multicolumn{3}{|c|}{$\begin{array}{c}\text { Pulmonary Artery } \\
\text { (mm.Hg) }\end{array}$} \\
\hline & & $\begin{array}{l}\text { Sys- } \\
\text { tolic }\end{array}$ & $\begin{array}{l}\text { Dias- } \\
\text { tolic }\end{array}$ & Mean & $\begin{array}{l}\text { Sys- } \\
\text { tolic }\end{array}$ & $\begin{array}{l}\text { Dias- } \\
\text { tolic }\end{array}$ & Mean \\
\hline $\begin{array}{c}\text { Controls } \\
1 \\
2 \\
2 \\
3 \\
4 \\
5\end{array}$ & $\begin{array}{l}\text { ND } \\
\text { ND } \\
\text { ND } \\
\text { ND } \\
\text { ND }\end{array}$ & $\begin{array}{l}\text { ND } \\
\text { ND } \\
\text { ND } \\
\text { ND } \\
\text { ND }\end{array}$ & $\begin{array}{l}\text { ND } \\
\text { ND } \\
\text { ND } \\
\text { ND } \\
\text { ND }\end{array}$ & $\begin{array}{l}\text { ND } \\
\text { ND } \\
\text { ND } \\
\text { ND } \\
\text { ND }\end{array}$ & $\begin{array}{l}20 \\
23 \\
27 \\
35 \cdot 1 \\
24 \cdot 7\end{array}$ & $\begin{array}{l}15 \\
16 \cdot 5 \\
19 \cdot 5 \\
19 \cdot 5 \\
14 \cdot 3\end{array}$ & $\begin{array}{l}17.5 \\
14.0 \\
22.5 \\
26.0 \\
19.5\end{array}$ \\
\hline $\begin{array}{l}\text { Opera- } \\
\text { tions } \\
\text { C-838 } \\
\text { C-1006 } \\
\text { D-325 } \\
\text { D-32 } \\
\text { D-1092 } \\
\text { D-164 } \\
\text { C-1002 } \\
\text { C-513 } \\
\text { D-320 }\end{array}$ & $\begin{array}{r}5 \\
8 \\
10 \\
5 \\
4 \\
5 \\
5 \\
4 \\
3\end{array}$ & $\begin{array}{l}30 \\
25 \\
52 \\
42 \\
40 \\
23 \\
42 \\
40 \\
22\end{array}$ & $\begin{array}{l}0 \\
0 \\
0 \\
5 \\
0 \\
0 \\
8 \\
8 \\
7\end{array}$ & $\begin{array}{l}12 \\
10 \\
30 \\
23 \cdot 5 \\
16 \\
8 \\
22 \\
26 \\
5\end{array}$ & $\begin{array}{l}18 \\
20 \\
48 \\
45 \\
25 \\
18 \\
38 \\
45 \\
20\end{array}$ & $\begin{array}{r}8 \\
10 \\
30 \\
30 \\
14 \\
7 \\
25 \\
25 \\
8\end{array}$ & $\begin{array}{l}10 \\
12 \\
35 \\
36 \\
20 \\
12 \\
30 \\
26 \\
10\end{array}$ \\
\hline
\end{tabular}

ND = not done.
Cardiac catheterization was carried out on nine of the operated dogs (Table IV).

Pulmonary angiograms were performed on eight of the operated dogs. In seven of these the angiograms were within normal limits. In the eighth dog there was no filling of the left pulmonary artery branches and subsequent necropsy revealed a left bronchostenosis with an almost completely fibrotic left lung.

Arterial blood samples were obtained by percutaneous puncture of the femoral artery in the unanaesthetized dog in 13 cases; these samples were analysed using the Radiometer Astrup. The results are presented in Table $V$.

It had been decided at this time to sacrifice the group of dogs on which the foregoing studies had been completed and to carry out histological studies on the re-implanted lung.

An opportunity occurred to do lung scans on two animals, and the results were interesting enough to influence us to delay the histological studies on the remainder until further lung scans could be done. 
T A B L E V

BLOOD GASES (mm. Hg)

\begin{tabular}{|c|c|c|c|c|}
\hline Dog & $\mathbf{P a H}$ & $\mathrm{PaCO}_{2}$ & $\mathrm{PaO}_{2}$ & $\begin{array}{l}\mathbf{H b} \mathbf{O}_{\mathbf{2}}(\%) \\
\text { Saturation }\end{array}$ \\
\hline $\begin{array}{c}\text { Controls } \\
1 \\
2 \\
3 \\
4 \\
4 \\
5\end{array}$ & $\begin{array}{l}7.53 \\
7.39 \\
7.39 \\
7.40 \\
7.34\end{array}$ & $\begin{array}{l}17 \cdot 0 \\
27 \cdot 1 \\
25 \cdot 2 \\
20 \cdot 5 \\
31 \cdot 0\end{array}$ & $\begin{array}{r}90.0 \\
100.0 \\
72.0 \\
85.0 \\
64.0\end{array}$ & $\begin{array}{l}97 \\
96 \\
93 \\
96 \\
90\end{array}$ \\
\hline $\begin{array}{c}\text { Operations } \\
\text { D-164 } \\
\text { D-1092 } \\
\text { C-838 } \\
\text { C-721 } \\
\text { C-1102 } \\
\text { C-513 } \\
\text { C-97 } \\
\text { C-1006 } \\
\text { D-320 } \\
\text { D-32 } \\
\text { D-313 } \\
\text { C-324 } \\
\text { C-325 }\end{array}$ & $\begin{array}{l}7.55 \\
7.39 \\
7.46 \\
7.47 \\
7.44 \\
7.44 \\
7.50 \\
7.45 \\
7.41 \\
7.47 \\
7.43 \\
7.42 \\
7.44\end{array}$ & $\begin{array}{l}37.0 \\
48.5 \\
65.0 \\
41.0 \\
42.0 \\
36.0 \\
24.0 \\
30.0 \\
33.0 \\
35.5 \\
43.0 \\
35.0 \\
40.0\end{array}$ & $\begin{array}{l}80 \\
62 \\
64 \\
65 \\
55 \\
62 \\
54 \\
62 \\
64 \\
55 \\
59 \\
56 \\
58\end{array}$ & $\begin{array}{l}96 \\
92 \\
93 \\
93 \\
87 \\
90 \\
88 \\
91 \\
91 \\
89 \\
90 \\
87 \\
89\end{array}$ \\
\hline
\end{tabular}

In the two dogs which had lung scans, D-32 and C-1006, differential spirometry was within expected limits. Pulmonary artery pressure was normal in one $\operatorname{dog}(\mathrm{C}-1006)$ and significantly elevated in the other. Pulmonary angiograms on both dogs were normal. Both dogs were examined longer than 7 months postoperatively.
In both cases the lung scan in the re-implanted lung was abnormal. Both these dogs were sacrificed and the lungs were immediately inflated with a $10 \%$ formalin solution.

Gross examination of the re-implanted lung in dog C-1006 showed a normal lung except for some small, patchy areas of what appeared to be healed infarction (Fig. 3).

In dog D-32 the upper lobe vein was stenosed and the upper lobe was fibrotic.

Examination of the lung scan suggested that either the vessels of 30 microns diameter or less were thrombosed or that shunting had occurred below this level so that many aggregates were not retained in the lung.

Lung scans were then performed on the remaining eight dogs. In four the lung scan appeared normal, and in the other four there was very little retention of radioactivity in the re-implanted lung.

The four animals that showed abnormal scans on the re-implanted lung were subjected to removal of the re-implanted lung. The histological picture of these lungs showed slight fibrous thickening of the overlying pleura and underlying areas of atelectasis and alternating emphysema and a slight degree of interstitial fibrosis, but there was no inflammatory cell infiltrate and nothing to be interpreted as a pneumonic process.

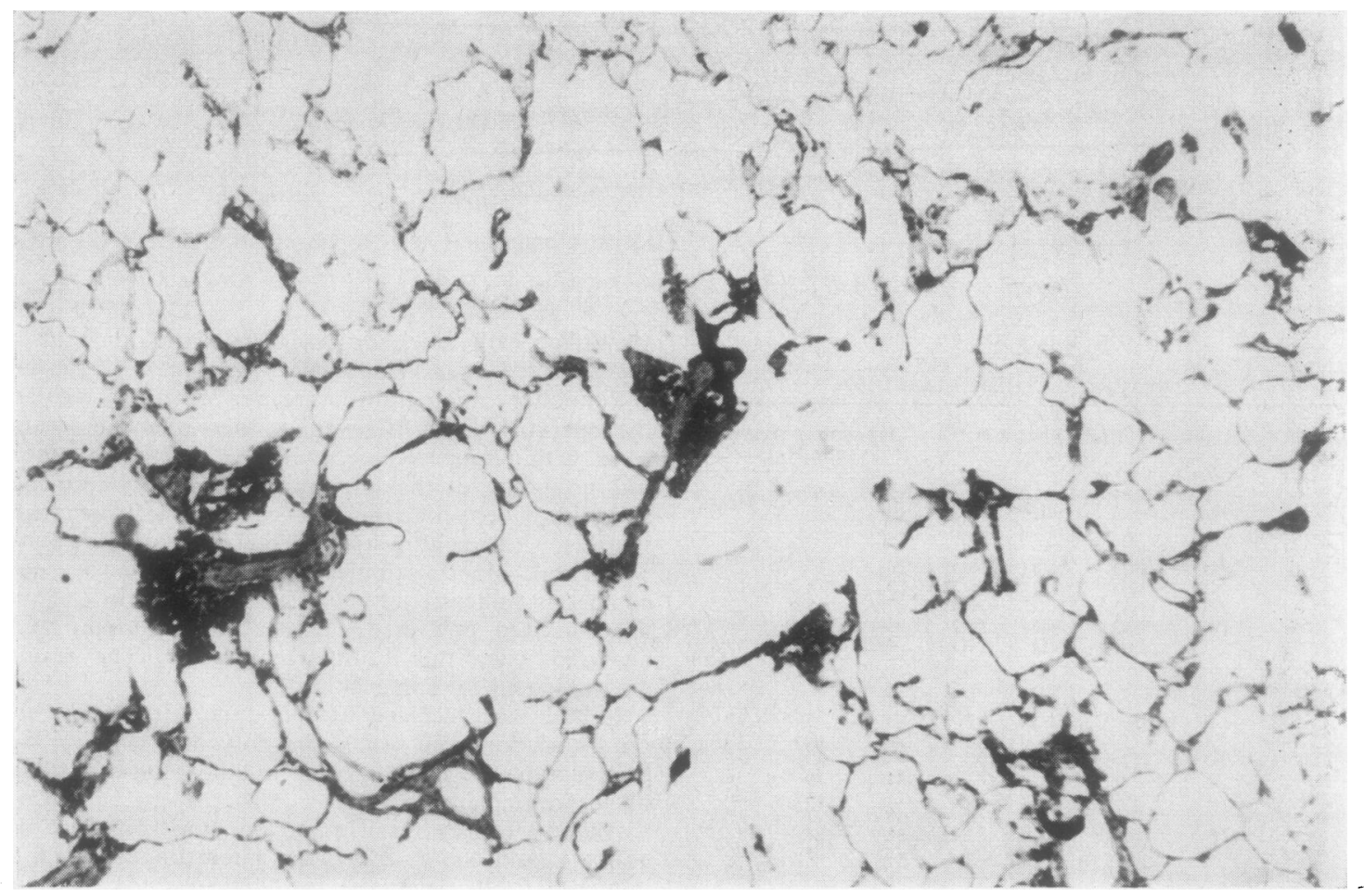

FIG. 3. Dog C-1006. Microscopic appearance of the re-implanted lung. 
The four animals that showed relatively normal lung scans (Fig. 4) were selected for contralateral pneumonectomy. The results are as follows:

All four dogs were first subjected to exploratory thoracotomy. In two cases considerable pleural peel was encountered. These animals were treated by decortication and then subjected to pneumonectomy three weeks later. The other two dogs showed normal lungs and pleural cavities. These animals were subjected to staged pneumonectomies.

Of the two dogs treated by acute total pneumonectomy, one lived for 24 hours. The other lived for five days. The dog that lived for 24 hours died in acute pulmonary oedema. The dog that survived for five days was active and eating and drinking normally for four days. It then developed evidence of early pulmonary oedema. It died of pulmonary oedema on the fifth day post-operatively.

The two dogs subjected to staged pneumonectomy had first the upper lobe and then the middle lobe removed at intervals of two weeks. At this stage both dogs were normal as far as activity was concerned. They appeared clinically to have adequate respiratory function. No tests were done at this stage to avoid the hazards of extra anaesthetic and operative risks. One of these dogs died during induction of anaesthesia for the final stage of pneumonectomy. It was not then realized that these animals will not tolerate an ordinary induction dose of nembutal.

The one remaining dog survived completion of pneumonectomy for 25 days. During this time it was active without clinical evidence of respiratory

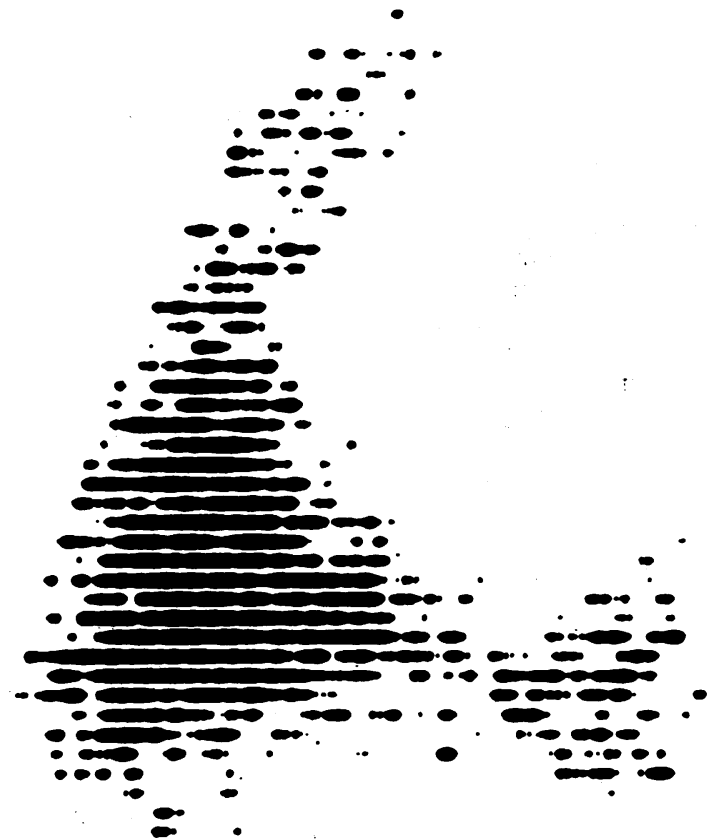

FIG. 4. Lung scan of one of the dogs selected for contralateral pneumonectomy. insufficiency. The breathing pattern responded to exercise by an increase in both the rate and depth of respiration. The venous blood showed normal oxygenation and $\mathrm{CO}_{2}$ levels. This animal died while trying to escape through a small opening in the door of the cage.

At necropsy the lung showed pulmonary oedema. The upper vein orifice was markedly narrowed. It should be noted that previous studies on this animal (C-513) had shown an elevated pulmonary artery pressure. Histological studies showed the lung to be normal except for pulmonary oedema.

\section{CONCLUSIONS}

From the results of this experimental work the following conclusions seem to be valid:

1. Lungs preserved by the method described will remain viable and survive re-implantation. The same method of preservation could probably be used for lungs intended for transplantation.

2. The re-implanted lung will, even though the nerve supply has been transected, eventually function in a normal manner.

3. Survival of the animals, on the re-implanted lung, with excellent respiratory function, is possible after contralateral pneumonectomy.

4. Incomplete survival of the re-implanted lung is due to problems associated with the technique of re-implantation.

5. Pulmonary hypertension commonly reported in re-implanted lungs is probably due to pulmonary vein stenosis. The aetiology of this is, as yet, not understood.

6. A return of the Hering-Breuer reflex may indicate regeneration of the nerve supply to the re-implanted lung.

7. Further extension of preservation times is indicated to try to determine the limits of preservation by this method.

We wish to thank the Canadian Tuberculosis Association and the Edmonton Civic Employees' Association for financial support of this project.

We also acknowledge the assistance of Dr. S. M. Le Ber, Department of Pathology, Royal Alexandra Hospital, Edmonton, for the interpretation of the histological preparations.

We are indebted to Mrs. D. Weijer and her assistants, of the University of Alberta Radioisotope Scanning Laboratory, for the lung scans.

\section{REFERENCES}

Blumenstock, D. A., Lempert, N., and Morgado, F. (1965). Preservation of the canine lung in vitro for 24 hours with the use of hypothermia and hyperbaric oxygen. J. thorac. cardiovasc. Surg., $50,769$.

Métras, H. (1950). Note préliminaire sur la grefie totale du poumon chez le chien. C.R. Acad. Sci. (Paris), 231, 1176.

Nigro, S. L., Evans, R. H., Benfield, J. R., Gago, O., Fry, W. A., and Adams, W. E. (1963). Physiologic alterations of cardiopulmonary function in dogs living one and one-half years on only a reimplanted right lung. J. thorac. cardiovasc. Surg., 46, 598. 